\title{
Sedation Free Colonoscopy: Patients' Characteristics and satisfaction in a hospital based Endoscopy Unit
}

\author{
Amit Kumar ${ }^{1 *}$, Rahul Pathak ${ }^{2}$ \\ ${ }^{1}$ Department of Surgery, Kantipur Dental College Teaching Hospital and Research Centre, Basundhara, Kathmandu , Nepal \\ ${ }^{2}$ Department of Gastroenterology, Institute of Medicine, Tribhuvan University, Kathmandu.
}

\section{DOI Name}

http://dx.doi.org/10.3126/jaim.v4i2.16895

\section{Keywords}

Colonoscopy; Pain measurement; sedative; without sedation

\section{Citation}

Amit Kumar, Rahul Pathak. Sedation free colonoscopy: patients' characteristics and satisfaction in a hospital based endoscopy unit. Journal of Advances in Internal Medicine 2015;04(02):45-50.

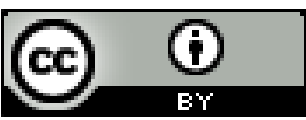

This work is licensed under a Creative Commons Attribution 3.0 Unported License.

\section{ABSTRACT}

Background and aims: Colonoscopy without sedation costs less and is more convenient than sedated colonoscopy and is the main mode of examination in our settings. The aims of the present study is to determine the percentage of patients who can successfully undergo unsedated colonoscopy and the factors contributing to patient satisfaction following the examination.

Material and Methods: Demographic, clinical, and colonoscopy related data were prospectively evaluated in 113 patients undergoing unsedated colonoscopy by an experienced endoscopist during the period of October 2015 to January 2016 at a single hospital based endoscopy setup. All colonoscopies routinely began without sedation and was curtailed if the patient or physician desired. Age, sex, prior abdominal operation, pain during examination and the time required to complete the colonoscopy were recorded. The patients were asked to rate their pain on scale of 0 to 10 , their satisfaction and willingness to undergo colonoscopy without sedation in future if required.

Results: In a total of 113 patients (mean age of 54.01 years) undergoing sedation free colonoscopy, 108 (95.5\%) required no sedation. Complete colonoscopy was done in 106 of the 108 and 110 of the 113 patients. The mean pain score was 2.58 in an average time taken of 11.9 minutes. Average time for intubation taken in post-operative patients $(n=20)$ was 12.24 minutes. $96(84.9 \%)$ of the patients were completely or well satisfied with the examination and $7(6.2 \%)$ were not satisfied with the procedure. There was not much difference in pain perception or satisfaction based on gender.

Conclusion: Colonoscopy without sedation can be completed successfully in a vast majority of patients with proper technique by experienced endoscopist. The practice saves time and money and patients are willing to return for future examinations if required. The facility of sedation should be present if required for any reason.

\section{INTRODUCTION}

Colonoscopy has become an indispensible tool for screening, diagnostic as well as therapeutic purposes for lower gastrointestinal diseases. Colonoscopy in patients can be done under sedation or without sedation, determined by local factors to a large extent. ${ }^{1}$ The direct and indirect cost of sedation or colonoscopy under anaesthesia makes it an expensive proposition and has got many disadvantages. ${ }^{2}$ In

\footnotetext{
* Corresponding author

Dr Amit Kumar, MBBS, M.S., Department of Surgery,

Kantipur Dental College Teaching Hospital and Research Centre,

Basundhara, Kathmandu, Nepal.

Email:dramitkr@hotmail.com
} 
many countries colonoscopy is performed mostly under deep sedation whereas in other place most colonoscopies are done without sedation. ${ }^{3,4}$ The preparation time for the procedure is increased. In colonoscopy under sedation the cost of nursing staff and covering anesthesiologist, requirement of recovery area and equipments are all added onto the procedure cost which makes it quite expensive. ${ }^{5}$ The patients also require more preparation and presence of accompanying person for the post procedure period besides requiring extra time for recovery. Comfort during and after colonoscopy represents a major issue for patient tolerance and acceptance, recommended longer withdrawal times at the same time keeping the cost low. Unsedated colonoscopy has been the standard in our country and in many places around the world. ${ }^{6}$ There have been very few studies on colonoscopy without sedation from our part of region. $^{7}$

Sedated colonoscopy has many downside associated with opportunity cost and the fiscal cost of sedation itself which act as barriers to examination. ${ }^{8}$ In this prospective study we aim to observe the patient experience and acceptance of unsedated colonoscopy and successful examination under our settings.

\section{Material and Methods}

All patients undergoing colonoscopy during the period of June to November 2015 were prospectively evaluated and included in the study.

Indoor patients or patients having known conditions precluding unsedated colonoscopy like recent AMI, significant discomfort or comorbidity, or those undergoing additional procedures were excluded from the study. The study was approved by the Institutional review board. Written patient consent was obtained for each patient for colonoscopy and for the study receiving patient study information including an informed consent section on a visit at the scheduling or earlier consultation. Referral details and initial diagnosis, age sex weight of the patients were recorded before the procedure.

Bowel preparation was done in a standard manner using polyethelene glycol in 2-2.5 liters of electrolyte solution taken 12-18 hours before the examination on an OPD basis. Patients continued taking clear liquids orally. The endoscopist graded the quality of bowel preparation as grade 1 if colon was clearly visualized with no stool, grade 2 as satisfactory with small amount of stool but not blocking the visualization and grade 3 where the colon preparation was unsatisfactory with stool blocking the view or the passage of colonoscope. Colonoscopic examination was performed using a videocolonoscope(Fujinon EC530) using air for insufflation and assisted by a trained nurse. The assessment was made by another trained nurse who was an observer. The primary endpoint of the present investigation was overall pain scores. Secondary endpoints was overall satisfaction assessed on a 10-point visual analogue scale (VAS) before and after the examination. The grading of the VAS were as follows: for pain: $0=$ no pain at all, $10=$ worst possible pain; for bloating or post procedure discomfort was also recorded on four point scale varying from no bloating to severe discomfort. Acceptance of the procedure was graded into four categories: Excellent, good, fair and poor or not acceptable at all.

During the procedure all patient were monitored for non invasive blood pressure (NIBP), pulse, oxygen saturation and ECG monitoring using monitors. As quality indicators and characteristics of the performed colonoscopy time to reach the ileum or caecum, withdrawal time, length of intervention, procedural length, and the number and the size $(>1 \mathrm{~cm},<1 \mathrm{~cm}$, small polyp $<5 \mathrm{~mm}$ ) of removed polyps were assessed. Patient and observer perception of pain was recorded; quality of bowel preparation and success in visualization of caecum was also noted and tabulated. ${ }^{9}$ Supplemental oxygen and venous lines were available for but not used in these patients. The study was discontinued if the patients developed significant discomfort, severe pain or unable to tolerate the procedure. Finally, peri-procedural complications were registered as well as time to discharge, cutting short the procedure due to pain or discomfort, oxygen supply, and other medication given were noted. The patients were asked at discharge to fill out the post procedure survey regarding pain, bloating, and satisfaction.

\section{Statistical analysis}

The observed data was tabulated and entered into Microsoft excel files and further analyzed.

\section{RESULTS}

In total 113 patients were present in the study and underwent colonoscopy without sedation. In the 53 were males and 60 were females (53.09\%). The average age the study group was 54.01 varying from 26 to 84 years. The patients demographics is shown in table 1. In the study group of the total patients 111 were able to complete the procedure without sedation. 
Table 1. Patient Characteristics at presentation

\begin{tabular}{|l|l|}
\hline Total number of Patients & 113 \\
\hline $\begin{array}{l}\text { Age (years) } \\
\text { Mean } \\
\text { Range }\end{array}$ & $\begin{array}{l}54.01 \\
26 \text { years to } 84 \text { Years }\end{array}$ \\
\hline $\begin{array}{l}\text { Gender } \\
\text { Males } \\
\text { Females }\end{array}$ & $53(46.9 \%)$ \\
\hline $\begin{array}{l}\text { Indications for Colonoscopy } \\
\text { Chief Complaint }\end{array}$ & $60(53.1 \%)$ \\
\hline Bleeding & $23(20.35 \%)$ \\
\hline Anemia & $21(18.6 \%)$ \\
\hline Abdominal Pain & $19(14.6)$ \\
\hline Diarrhoea & $10(8.8)$ \\
\hline Constipation & $6(5.3 \%)$ \\
\hline Bloating/Incomplete evacuation & $12(10.6 \%)$ \\
\hline Irritable bowel syndrome & $4(3.5 \%)$ \\
\hline Others & $18(15.92 \%)$ \\
\hline $\begin{array}{l}\text { Patient with previous abdominal } \\
\text { operations }\end{array}$ & $20(12$ females, 8 males) \\
\hline
\end{tabular}

Complete examination up till caecum was achieved in 109 patients. The time taken to reach caecum was similar in both males and females; the average time of caecal intubation being 11.86 minutes. The study was considered successful if the colonoscope could be passed to the caecum or into terminal ileum. Caecal intubation was achieved in 109 out of 113 patients including 2 patients who required sedation.

20 patients had history of prior abdominal operations 12 females and 8 males. The female patient had mostly undergone hysterectomy or cholecystectomy while the male patients had undergone emergency abdominal surgery including Appendicectomy. The pain reporting by patient who had undergone abdominal operations was 3.02 which was slightly more than 2.48 when compared to rest of the study group.

The indication for colonoscopy included Rectal bleeding ( $n=23,20.35 \%)$, abdominal pain(19,16.8\%), loose stool or constipation(10 and 6 respectively) or irregular bowel habit(4), bloating or incomplete evacuation(12) and others(18). Some patients had more than one complaint at presentation.

As per the bowel preparation criteria, the bowel preparation was adequate in 106 patients and inadequate in 7 patients. Complete examination could not be completed in 3 patients following presence of stool. Bowel preparation in most patients was adequate with 86 patient had very good preparation, 20 had good or satisfactory preparation and 7 patients had unsatisfactory preparation. Good preparation increases the reliability and technical ease of examination. ${ }^{9}$

Colonoscopy could be completed in 110 patients; 52 males and 58 females. 3 patients requested to pause the examination due to discomfort which was subsequently completed under sedation. In 27 patients maximum pain occurred at the time of intubation of ascending colon and in 12 at the approximate level of transverse colon.

Of the 113 patients, the colonoscopy was normal in 46 patients. Colonic polyp was the most common diagnosis( $n=20,17.7 \%)$, inflammatory bowel disease was present in $7(6.2 \%)$ patients, colorectal mass seen in 5 patients. Nineteen(16.81\%) patients had non- specific colitis or Proctitis and 21 patients had haemorrhoids in some cases associated with other pathology as well.

\section{Pain and Procedure acceptance}

The average pain score was 2.58 on a scale of 0 to 10 ( 0 to 8 ) amongst those who had complete examination up till caecum. Amongst those who had previous abdominal operations $(n=20)$ the average pain score was 3.02. the difference was quite small and non significant. The average pain score as assessed by the observer 38 patients had minimal or no pain. 44 patients had transient pain or small amount of pain( score 2-4). 26 patients complained of pain multiple times and 6 patients had severe pain or curtailed their procedure.

Thirty six (31.8\%) complained of bothersome bloating following the procedure and this was not bothersome in others.

The average patient satisfaction score was 7.48 on Visual Analog Scale. Fifty nine( 52\%)patients were highly happy with their examination, 32 were satisfied and 6 were uncomfortable and very dissatisfied.

\section{Procedure time}

The average time taken to complete the caecal intubation was 11.9 minutes with time ranging from 8.1 minutes to 24 $(S D \pm 2.17)$ minutes amongst those who underwent complete examination without sedation.

Satisfaction from the procedure as measured by post procedure scoring and willingness to repeat the procedure if required was quite high with 91 (80.5\%) satisfied or highly satisfied. Sixteen (14.15\%) patients found unsedated colonoscopy to be fair or had no opinion regarding future preference. Six (5.3\%) patients were not satisfied or wanted sedation or some other 
intervention in subsequent sitting. Table 2

Table 2. Outcome of Colonoscopy Examination

\begin{tabular}{|l|l|}
\hline Total Number of Patients & 113 \\
\hline Complete Examination till Caecum/ & 109 (Unsedated \\
ileum & 107 ) \\
\hline Findings: & \\
Normal & 46 \\
Polyps & 20 \\
Non specific Colitis/Proctitis & 19 \\
Colonic mass & 5 \\
Tuberculosis & 6 \\
Ulcerative colitis & 7 \\
Haemorrhoids & 21 (incl. those with \\
& other pathology) \\
\hline Incomplete examination & 5 \\
Inadequate bowel preparation & 3 \\
Pain during procedure & 2 ( required sedation) \\
Technical difficulty & 1 \\
\hline Time for examination & 11.9 minutes \\
\hline Bowel preparation quality & \\
1 & 86 \\
2 & 20 \\
3 & 7 \\
\hline Satisfaction with the procedure & \\
Highly satisfied & 59 \\
Good & 32 \\
Fair & 16 \\
Poor or & 6 \\
Not satisfied & \\
\hline & \\
Average time taken & deviation \pm 2.17 ) \\
Average time taken in post & 12.24 minutes \\
operative Patients(20) & \\
\hline
\end{tabular}

\section{DISCUSSION}

Video colonoscopy is one of the primary investigations in screening and detection of colorectal cancer and other causes of lower gastrointestinal bleeding. Negotiating an optical colonoscope thorough the lower GI tract along the multiple bends and variations in anatomy can be painful and possibly cause multiple complications depending upon the instruments used, physician proficiency or patient related factors like adhesions and apprehension. Other factors causing pain and dissatisfaction can be related to endoscopist, over insufflation, loop formation, stiffness of scope and anatomical or visual distortions. A number of studies have been done to improve on these factors like using carbon dioxide ( $\mathrm{CO} 2)$ or water instillation, change of techniques or magnetic positional endoscopes. ${ }^{10,11,12}$
The use of routine sedation is to an extent dependent upon cultural factors and practice patterns. ${ }^{13,14,15,16}$ Routine sedation has been shown to slightly increase complications and may also cause bradycardia or episodes of hypoxia and rarely death due to these complications. ${ }^{2,13,17}$ In our institution most colonoscopy examinations are done without sedation with presence of backup anaesthesia in the same facility for rescue in case it is needed. The procedure is widely accepted amongst patients as no admission or extended observation is required, requirement of escort or assistance is also reduced thus keeping overall cost of the procedure low and increasing the acceptability of the procedure. In this study of 113 patients none had severe changes in heart rate or fall in oxygen saturation below $93 \%$ of $\mathrm{SpO} 2$.

In some countries sedation during colonoscopy is much more prevalent as it provides pain free experience and has greater acceptability amongst patients ${ }^{18,19}$ but may have more complication like bleeding, perforation and anaesthesia mishaps. ${ }^{2}$ In this study of 113 patients; none of the patients had bradycardia or hypoxic episodes (oxygen saturation falling below $93 \%$ ) during the procedure.

In 36 patients colonoscopy could be completed with minimal pain(pain score<2) while 46 had mild to moderate pain at times during the examination. Two had severe pain or discomfort such that it was later completed under sedation. This finding is similar to those found in study by Turkish study and in Cataldo et al. ${ }^{5,17}$ There was not much of a difference between older and younger cohorts of patients' perception of pain as documented by Holme et al., they also find that an age of less than 40 years, diverticulitis and previous surgery as having increases incidence of pain in unsedated colonoscopy. ${ }^{18}$ In Saudi Arabian study by AlJabreen average pain score was 5.7 for the unsedated group which was marginally higher than that seen in our study with $7.5 \%$ having bad experience in unsedated colonoscopy. ${ }^{19}$ In their study Petrini et al. had $99 \%$ caecal intubation rate but this was much lower in case of females. $^{20}$

In this study complete colonoscopy examination could be done in $96 \%$ of the patients. There is not much difference in the proportions of complete examination between sedated and non sedated patients. Aljebreen et al had a completion rate of $85.9 \%$ vs. $84.2 \%$ with an average examination time of 11.8 minutes and significantly early discharge of patients in 20.7 minutes on average in unsedated persons. ${ }^{21} 77.3 \%$ of patients in the unsedated group were willing to undergo similar repeat examination vs. $83.3 \%$ in the sedated group. Petrini had a completion rate of $81.3 \%$ while Takahashi et al 
had completion rate of $99 \%$ in their study. ${ }^{11,20} \mathrm{As}$ per Yu et al the completion rate was $98 \%$ and there was high correlation between the Endoscopist and pain free examination of the colon till caecum. ${ }^{10}$ Completing the examination in single sitting is important as it obviates the need to reexamine or reschedule; thus negating the advantages of unsedated colonoscopy besides increasing the cost. Petrini et al. find that previous operations caused the unsedated complete examination to drop significantly to just $67 \%$. As per Cotton PB the completeness rate of discomfort examination was operator dependent wherein 55\% of colonoscopies achieved a caecal intubation rate of $>90 \%$ and for $9 \%$ of physicians this was less than $80 \%$ of examinations. ${ }^{22}$

In south Asia region there is no national program for colorectal cancer screening so most colonoscopies are done in symptomatic patients and quite a large number of people have unattended surgical or endoscopy requirement that are ignored. ${ }^{23}$ In our group of patients $23(20.35 \%)$ of the examination was for bleeding , 21(18.5\%) for anemia. The indications are shown in table 1 . The incidence is similar to those seen in the Turkish study with bleeding being the most common cause. In a Saudi Arabian study by Aljebreen in unsedated patients study the most frequent indication was rectal bleeding (24\%) followed by pain, diarrhea and constipation. ${ }^{17,19}$

The barriers to acceptance of unsedated colonoscopy are the perceived pain and anticipatory anxiety induced by that. According to Mizukami and study from Taiwan pain is dependent on the endoscopist and the technique used. ${ }^{24,25}$ Discomfort and pain are related to bowel wall distention as well as mesenteric stretch. Avoidance of over distention while using air insufflation keeps the patient comfortable. Herman in his study had a failure rate of just $5 \%$. In our study the study could

\section{REFERENCES}

1. Ladas S D, Satake Y, Mostafa I. et al. Sedation practices for gastrointestinal endoscopy in Europe, North America, Asia, Africa and Australia. Digestion. 2010;82:74-76. [PubMed]

2. Frieling $T$, Heise J, Kreysel C, Kuhlen R, Schepke $M$. Sedation-associated complications in endoscopy-prospective multicentre survey of 191142 patients. Z Gastroenterol. 2013 Jun;51(6):568-72

3. Ristikankare $M$, Hartikainen J, Heikkinen $M$, Janatuinen $E$, Julkunen $R$. Is routinely given conscious sedation of benefit during colonoscopy? Gastrointest Endosc. 1999 be completed comfortably in $94 \%$ of the patients. ${ }^{26}$ Mizukami et al. have described collapse and submergence method to avoid pain associated with air inflation and achieved excellent results. ${ }^{24}$ Leung et al. in their study of unsedated colonoscopy by trainee found the success rate to be quite good and well accepted by the patients. ${ }^{27}$

Overall in sedated and on demand sedation with water method good outcomes while most responders did not recommend unsedated colonoscopy. ${ }^{4}$ Similarly Madan A. et al had very low acceptance rate of unsedated colonoscopy amongst healthcare workers and Siao-Salera et al. in their survey of medical personnel found overwhelming preference for endoscopy under sedation. ${ }^{28,29}$ As per Early DS et al. patients were much more accepting of colonoscopy without sedation after the procedure. ${ }^{30}$

In our study the patient acceptability is quite good with proper pre procedure counseling and nursing support as demonstrated by willingness to undergo similar procedure in future if required.

\section{CONCLUSION}

Unsedated colonoscopy is feasible and well accepted in 95\% of patients who accept the procedure. With proper technique and allaying of patient fears it can be done in most people. Some patients do require sedation. The major advantages of this procedure are the reduced expenditure, fast recovery and minimal observation required after completing the Colonoscopy, all of this matter in our circumstances. A larger randomized study comparing unsedated to sedated colonoscopy with patient satisfaction and quality parameters will be helpful.

May;49(5):566-72.

4. Rex DK, Imperiale TF, Portish V. Patients willing to try colonoscopy without sedation: associated clinical factors and results of a randomized controlled trial. Gastrointest Endosc. 1999;49:554-559. doi: 10.1016/ S0016-5107(99)70381-0.

5. Cataldo PA. Colonoscopy without sedation. Diseases of the Colon \& Rectum. 1996 Mar 1;39(3):257-61.

6. Terruzzi V, Paggi S, Amato A, Radaelli F. Unsedated colonoscopy: A neverending story. World J Gastrointest Endosc. 2012 Apr 16;4(4):137-41

7. Pradhan B, Pandey N. Colonoscopy in patients 
without sedation: an experience from Nepal. Health Renaissance. 2012;10(1):27-9.

8. Ko C. Hidden cost of sedation for screening and surveillance by optical colonoscopy. American Journal Clinical Medicine.2010;7(3):119-120.

9. Horiuchi A, Tanaka N. Improving quality measures in colonoscopy and its therapeutic intervention. World J Gastroenterol. 2014 Sep 28;20(36):13027-34.

10. Yu S-P, Lin X-D, Wu G-Y, Li S-H, Wen Z-Q, Cen X-H, et al. Unsedation colonoscopy can be not that painful: Evaluation of the effect of "Lamaze method of colonoscopy." World J Gastrointest Endosc. 2015 Oct 25;7(15):1191-6.

11. Takahashi Y, Tanaka H, Kinjo M, Sakumoto K. Sedationfree colonoscopy. Dis Colon Rectum. 2004;48:855-859. doi: 10.1007/s10350-004-0860-0.

12. Fukuzawa M, Uematsu J, Kono S, Suzuki S, Sato T, Yagi $\mathrm{N}$, et al. Clinical impact of endoscopy position detecting unit (UPD-3) for a non-sedated colonoscopy. World J Gastroenterol. 2015 Apr 28;21(16):4903-10.

13. Froehlich F, Harris JK, Wietlisbach V, Burnand B, Vader JP, Gonvers JJ, Fork T, Benoni C, EPAGE Study Group. EPAGE Study Group. Current sedation and monitoring practice for colonoscopy: an international observational study (EPAGE). Endoscopy. 2006;38(5):461-9.

14. Chung YW, Han DS, Yoo KS, Park CK. Patient factors predictive of pain and difficulty during sedation-free colonoscopy: a prospective study in Korea. Digestive and Liver Disease. 2007 Sep 30;39(9):872-6.

15. Leung FW, Aljebreen AM, Brocchi E, Chang EB, Liao W-C, Mizukami T, et al. Sedation-risk-free colonoscopy for minimizing the burden of colorectal cancer screening. World J Gastrointest Endosc. 2010 Mar 16;2(3):81-9.

16. Thiis-Evensen E, Hoff GS, Sauar J, Vatn MH. Patient tolerance of colonoscopy without sedation during screening examination for colorectal polyps. Gastrointestinal Endoscopy. 2000 Nov 30;52(5):606-10.

17. Yörük G, Aksöz K, Unsal B, Buyraç Z, Buran T, Yazicioğlu $\mathrm{N}$, Yildiz C, Yalçin HC. Colonoscopy without sedation. Turk J Gastroenterol. 2003 Mar;14(1):59-63.

18. Holme O, Bretthauer M, de Lange T, Seip B, HuppertzHauss G, Høie O, Sandvei P, Ystrøm CM, Hoff G. Risk stratification to predict pain during unsedated colonoscopy: results of a multicenter cohort study. Endoscopy. 2013 Sep;45(9):691-6. in a cohort of unsedated patients. Saudi Journal of Gastroenterology. 2004 Sep 1;10(3):150.

20. Petrini JL, Egan JV, Hahn WV. Unsedated colonoscopy: patient characteristics and satisfaction in a communitybased endoscopy unit. Gastrointest Endosc. 2009 Mar;69(3 Pt 1):567-72.

21. Aljebreen AM, Almadi MA, Leung FW. Sedated vs unsedated colonoscopy: a prospective study. World J Gastroenterol. 2014 May 7;20(17):5113-8.

22. Cotton PB, Connor P, McGee D, Jowell P, Nickl N, Schutz $\mathrm{S}$, Leung J, Lee J, Libby E. Colonoscopy: practice variation among 69 hospital-based endoscopists. Gastrointestinal endoscopy. 2003 Mar 31;57(3):352-7.

23. Tessler R, Gupta S, Pathak J, Ghimire P, Kingham TP, Kushner AL, Amatya KS, Nwomeh BC. Rectal bleeding and implications for surgical care in Nepal. Journal of Surgical Research. 2015 Jul 31;197(1):12-7.

24. Mizukami T, Yokoyama A, Imaeda H, Kumai K. Collapsesubmergence Method: Simple Colonoscopic Technique Combining Water Infusion With Complete Air Removal From The Rectosigmoid Colon. Digestive Endoscopy. 2007 Jan 1;19(1):43-8.

25. Liao WC, Chiu HM, Chen CC, Lee YC, Wu MS, Lin JT, Wu AS, Wang HP. A prospective evaluation of the feasibility of primary screening with unsedated colonoscopy. Gastrointestinal Endoscopy. 2009 Oct 31;70(4):724-31.

26. Herman, FN. Avoidance of sedation during total colonoscopy. Dis Colon Rectum 1990;33:70-72 PubMed

27. Leung FW, Aharonian HS, Guth PH, Chu SK, Nguyen BD, Simpson P. Involvement of trainees in routine unsedated colonoscopy: review of a pilot experience. Gastrointest Endosc. 2008 Apr;67(4):718-22.

28. Madan A, Minocha A. Who is willing to undergo endoscopy without sedation: patients, nurses, or the physicians?. Southern medical journal. 2004 Sep 1;97(9):800-6.

29. Siao-Salera R, Leung JW, Mann SK, Canete W, Gutierrez $\mathrm{R}$, Galzote $\mathrm{CR}$, et al. Options of sedation or no sedation for colonoscopy - the perspective of the GI nurses and technicians. J Interv Gastroenterol. 2011;1(1):37-41.

30. Early DS, Saifuddin T, Johnson JC, King PD, Marshall JB. Patient attitudes toward undergoing colonoscopy without sedation. Am J Gastroenterol. 1999;94:18621865. doi: 10.1111/j.1572-0241.1999.01219.x.

19. Aljebreen AM. The completeness rate of colonoscopy 